\title{
ESDD
}

3, 433-452, 2012

\section{Estimated impact of global population growth on future wilderness extent}

\section{E. Dumont}

Centre for Ecology \& Hydrology, Wallingford, UK

Received: 5 June 2012 - Accepted: 18 June 2012 - Published: 25 June 2012

Correspondence to: E. Dumont (egdu@ceh.ac.uk)

Published by Copernicus Publications on behalf of the European Geosciences Union.

Estimated impact of global population growth on future wilderness extent

E. Dumont

\section{Title Page}

Abstract

Conclusions

Tables

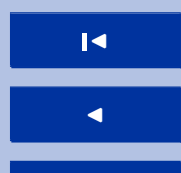

Back
Full Screen / Esc

Printer-friendly Version

Interactive Discussion

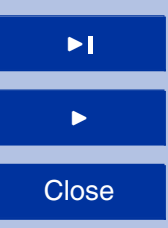

$>$

\section{lose}

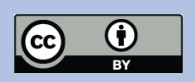




\section{Abstract}

Wilderness areas in the world are threatened by the environmental impacts of the growing global human population. This study estimates the impact of birth rate on the future surface area of biodiverse wilderness and on the proportion of this area without major 5 extinctions. The following four drivers are considered: human population growth (1), agricultural efficiency (2), groundwater drawdown by irrigation (3), and non-agricultural space used by humans (buildings, gardens, roads, etc.) (4). This study indicates that the surface area of biodiverse unmanaged land will reduce with about $5.4 \%$ between 2012 and 2050. Further, it indicates that the biodiverse land without major extinctions 10 will reduce with about $10.5 \%$. These percentages are based on a commonly used population trajectory which assumes that birth rates across the globe will reduce in a similar way as has occurred in the past in many developed countries. Future birth rate is however very uncertain. Plausible future birth rates lower than the expected rates lead to much smaller reductions in surface area of biodiverse unmanaged land $(0.7 \%$

15 as opposed to $5.4 \%$ ), and a reduction in the biodiverse land without major extinctions of about $5.6 \%$ (as opposed to $10.5 \%$ ). This indicates that birth rate is an important factor influencing the quality and quantity of wilderness remaining in the future.

\section{Introduction}

The world has limited resources, such as fertile land, energy, and raw materials, which

limit the amount of people that the world can sustain. Many studies have estimated this maximum amount of people (van den Bergh and Rietveld, 2004). Half of these studies estimate that less than 7.7 billion people can be sustained by the land that is available for food production on the earth. This indicates that all potential agricultural area is in production at a world population size of about 7.7 billion, thus leaving no space for
ESDD

3, 433-452, 2012

\section{Estimated impact of global population growth on future wilderness extent}

E. Dumont

\section{Title Page}


wilderness in this area ${ }^{1}$. This would be very serious since areas with soils and climates suitable for agricultural production are also likely to be the most suitable for highly biodiverse wilderness (Kleidon and Mooney, 2008). This is corroborated further by the model result of Dobrovolski et al. (2011) which predicts that future growth of agricultural 5 area will be about four times faster in high-biodiversity wilderness areas (Mittermeier et al., 2003) compared to other areas.

Space for wilderness has not yet not been considered as a factor limiting the human population, because wilderness is not absolutely essential to human survival. However, loss of wilderness irreplaceably diminishes an important source of human wellbeing. 10 Wilderness areas have many values extensively described in the literature. For example, Noss (1991) describes the following five values of wilderness: it tells ecologists what they should aim for when they try to restore disturbed ecosystems (1); it provides habitat for many species especially those at the top of the food chain requiring a large undisturbed areas (2); it can make us feel liberated from the pervasiveness of civi15 lization (3); it can sustain evolutionary potential for all species (4); and it has intrinsic value (5). Although intrinsic value cannot be shown, it is consistent with the notion of human dignity and the absence of any objective reason for believing that humans are fundamentally superior to any other species.

This study estimates the impact of different possible future trends in human birth 20 rates on the change in global wilderness area until the year 2050. This is done for four types of wilderness which are defined in the next section.

\footnotetext{
${ }^{1}$ Many of these estimates were made a few decades ago when the world population was much less close to 7.7 billion than the current world population of 7.0 billion. It is therefore likely that new estimates would give a higher world population limit.
}

ESDD

3, 433-452, 2012

\section{Estimated impact of global population growth on future wilderness extent}

E. Dumont

\section{Title Page}




\section{Methods}

First I will describe the used data on projected future global population for three different but plausible future birth rates. Subsequently, I will describe how I used these projected future human populations to estimate the future trend in global coverage of four types 5 of wilderness: unmanaged land (1), biodiverse unmanaged land (2), land without major extinctions (3), and biodiverse land without major extinctions (4).

This study was done on the global scale and no distinction was made between different world regions. The main reason for this is the uncertainty in the relation between population growth and wilderness on a regional level. For example, it is very unclear 10 how agricultural land expansion (at the expense of wilderness) in one region will be affected by demand for agricultural products by the population in another region. Further, the change in spatial distribution of wealth, driving conversion of wilderness to non-essential land uses such as recreational areas and residential areas, is uncertain. Finally, the spatial distribution of agricultural efficiency and its change in the future is 15 very uncertain.

\subsection{Future world population}

This study uses three projections of world population until 2050: the UN medium, high variant, and low variant projection (UN, 2010). These projections differ with respect to the assumed future fertility (number of children per woman). I will use each of these three projections to estimate future changes in global wilderness area. The medium variant represents the most likely future population according to the UN and the other two projections show the impact of different, but plausible, future birth rates on world population.
ESDD

3, 433-452, 2012

\section{Estimated impact of global population growth on future wilderness extent}

E. Dumont

\section{Title Page}

Abstract

Conclusions

Tables

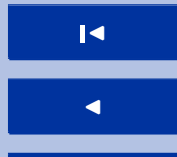

Back
Introduction

References

Figures

$\rightarrow 1$

Close
Full Screen / Esc

Printer-friendly Version

Interactive Discussion 


\subsubsection{UN medium population projection}

The UN medium projection is based on the UN's best estimate of future fertility which fits best with all past observed trends in fertility in individual countries. The UN medium projection implicitly assumes that fertility in less developed countries will decline, in a 5 similar way as has occurred in the recent history of many developed countries. As a result, the fertility of all countries is projected to decline toward the replacement level of 2.1 children per woman (albeit the rate and trajectory of this decline differs between countries). The medium variant is approximately in the middle of all possible population futures projected by the UN.

\subsubsection{UN high and low variant population projection}

The high variant projection assumes a slower decline in fertility than the medium variant. Therefore by $2020-2025$, the fertility in the high variant is 0.5 child higher than in the medium variant and remains 0.5 child higher until 2050 .

Likewise, the low variant projection assumes a faster decline in fertility than the 15 medium variant. Therefore by 2020-2025, the fertility in the low variant is 0.5 child lower than in the medium variant and remains 0.5 child lower until 2050.

\subsection{Low biodiversity areas with low wilderness losses}

The black area in Fig. 1 consists of desert and tundra (Rubel and Kottek, 2010) in which biodiversity is on average about five times lower than in grasslands and boreal forests which are the biomes with the second lowest biodiversity in the world (Kleidon and Mooney, 2000). In addition, the black area has very little expected future change in wilderness area due to its low population density ( $<1.5$ person $\mathrm{km}^{-2}$ based on GPWv3, 2005) and due to its unsuitability for agriculture (Houghton, 1994). In Sect. 3, the surface area of the black area $\left(21.5\right.$ million $\left.\mathrm{km}^{2}\right)$ is subtracted from the projected total
ESDD

3, 433-452, 2012

\section{Estimated impact of global population growth on future wilderness extent}

E. Dumont

\section{Title Page}

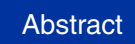

Introduction

Conclusions

References

Tables

Figures

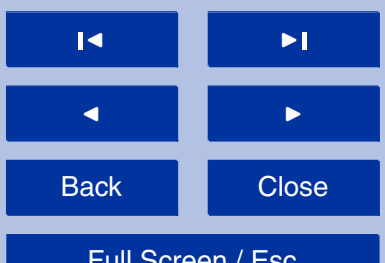

Full Screen / Esc

Printer-friendly Version

Interactive Discussion 
wilderness area to obtain an estimate of the biodiverse wilderness area (biodiverse unmanaged land or biodiverse land without major extinctions).

The grey area in Fig. 1 (112.0 million $\mathrm{km}^{2}$ ) has a higher biodiversity and may suffer significantly from loss of wilderness.

\section{2.3 Unmanaged land}

The global land area not managed for human use $\left(W^{\prime}(y)\right)$ is estimated as follows:

$W^{\prime}(y)=L-P(y) \cdot\left(A_{\text {pers }}(y)+U_{\text {pers }}\right)-I(y)$

Here $L$ is the global ice-free land surface area $\left(133.5\right.$ million $\left.\mathrm{km}^{2}\right), P(y)$ is the world population in year $y$ (persons), $A_{\text {pers }}(y)$ is the agricultural area needed to support the 10 average person in the world $\left(\mathrm{km}^{2}\right.$ person $\left.{ }^{-1}\right), U_{\text {pers }}$ is non-agricultural land used per person $\left(\mathrm{km}^{2}\right.$ person $\left.{ }^{-1}\right)$, e.g. gardens, golf courses, houses, libraries, roads, etc., and $I(y)$ is increase in agricultural area due to unsustainable irrigation $\left(\mathrm{km}^{2}\right)$.

Wilderness area is unlikely to increase in time, because it is probably impossible to create original wilderness. For example, a local species that has become extinct, due 15 to destruction of the wilderness that it depended on, can never return. Also, soil and surrounding ecosystems can irreversibly change after wilderness has been removed, making a return of the original wilderness impossible. To account for this, $W^{\prime}(y)$ is transformed to $W(y)$ using Eq. (2):

$W(y)=\operatorname{minimum}\left(W^{\prime}(i)\right.$ for $\left.i=2012 \ldots y\right)$

20 Here $W(y)$ is wilderness area in the world $\left(\mathrm{km}^{2}\right), i$ is an index variable taking all integer values from 2012 to year $y$ (the year for which $W(y)$ is calculated).

Wilderness area can be reduced by more than just current and past land management (Eqs. 1 and 2, respectively). Depending on the definition of wilderness, wilderness area can be further reduced by disturbances such as fragmentation (i.e. reduction of patch size) and hunting. This will be covered after the current section (Sect. 2.4).

ESDD

3, 433-452, 2012

Estimated impact of global population growth on future wilderness extent

E. Dumont

Title Page

Abstract Introduction

Conclusions References

Tables Figures

14

4

Back

Close

Full Screen / Esc

Printer-friendly Version

Interactive Discussion
$>1$

sc

(1) sion 
The global managed land surface consists mostly of agricultural land, and predictions of agricultural land area up to 2050 have been published in the scientific literature and reviewed by Smith et al. (2010). Nevertheless a new method for predicting agricultural area has been developed and used in this study to allow illustration of the effect of 5 different projected future global population sizes (corresponding to different future birth rates) on agricultural area. Furthermore, the method developed in this study incorporates more recent data, whereas literature estimates were made many years ago and do not include the most recent information (Smith et al., 2010).

\subsubsection{Agricultural area per person}

10 The global agricultural area (arable land plus grassland) has increased much in the recent decennia (Fig. 2a) to meet the increasing food and fiber demand of the growing world population (Klein Goldewijk et al., 2011). However, there have also been substantial increases in agricultural efficiency (global population divided through global agricultural area) during this period. In fact, FAOSTAT data indicate that global agricultural area would have increased about nine times faster if agricultural efficiency would not have improved since 1960 (Fig. 2b).

The global agricultural area reported in FAOSTAT starts decreasing after 2000 (Fig. 2a). This could be due to the fact that south, east, and central Asia have run out of space for agricultural expansion around 1995 (Fischer et al., 2002). Since then, 20 the fast growth of population and economy in this region has further increased land requirements for settlements and infrastructure leading to a continued decrease in space available for agriculture. This explanation is corroborated by FAOSTAT statistics which show that the decrease in agricultural area mainly occurs in south, east, and central Asia.

25 However, this recent stop in global agricultural land expansion is likely to be temporary, especially because there is still space for expansion, especially in the America's

\section{ESDD}

3, 433-452, 2012

\section{Estimated impact of global population growth on future wilderness extent}

E. Dumont

\section{Title Page}


(Fischer et al., 2002) ${ }^{2}$. In addition FAOSTAT shows that the rate of increase in calories used per person has not changed since 2000 , and this rate is not expected to decrease in the future due to the likely increasing demand for bio-fuels.

A linear trend can be fitted to the FAOSTAT statistics on global agricultural area 5 (Fig. 2a):

$$
A(y) \approx c_{1}+c_{2} y
$$

Here $A(y)$ is agricultural area $\left(\mathrm{km}^{2}\right)$, and $c_{1}$ and $c_{2}$ are constants fitted with regression. The values of $c_{1}$ and $c_{2}$ are given in Table 1 . The suitability of Eq. (3) is indicated by a Pearson correlation of 0.96 between $A(y)$ and $y$.

An alternative interpretation of FAOSTAT land use statistics is given by Bruinsma (2009). He states that a number of literature sources indicate that FAOSTAT data on arable land area for several developing countries (in particular China) are unreliable, resulting in unrealistic growth rates from 1983 onwards. Therefore Bruinsma (2009) has adjusted the FAOSTAT data on arable land and land under permanent crops. The insma (2009) fitted a linear time trend to his adjusted data. I used the fitted intercept and slope of this fitted trend to derive alternative values of coefficients $c_{1}$ and $c_{2}$ (Eq. 3), respectively (Table 1 ). I did this by multiplication with 3.22 , which is the ratio of global agricultural area (modelled by Eq. 3) over arable land area plus land area under perthe 1960-2009 period in FAOSTAT data (maximum deviation: 1.3\%).

Agricultural area $(A(y))$ modelled by Eq. (3) is used as follows to estimate agricultural area per person $\left(A_{\text {pers }}(y)\right)$ :

$A_{\text {pers }}(y) \approx \frac{A(y)}{c_{3}+c_{4} y}$

${ }^{2}$ Around 1995, 20 and $27 \%$ of the land under forest ecosystems in South and North America, respectively, had good potential for use as cropland (Fischer et al., 2002).

440
ESDD

3, 433-452, 2012

\section{Estimated impact of global population growth on future wilderness extent}

E. Dumont

\section{Title Page}

\section{Full Screen / Esc}

Printer-friendly Version

Interactive Discussion 
Here, $c_{3}$ and $c_{4}$ are constants fitted with regression. Their values are $-1.54 \times 10^{11}$ and $8.03 \times 10^{7}$, respectively. The nominator in Eq. (4) is an estimate of world population fitted for the period 1960-2009. The suitability of the nominator for estimating past population is indicated by a Pearson correlation of 1.0 between past world population

5 and $y$. Agricultural area per person $\left(A_{\text {pers }}(y)\right)$ modelled with Eq. (4) reduces with time but can never become zero, as one would expect.

Climate change is not included in the calculation of $A_{\text {pers }}(y)$ because currently the impacts of climate change on global-scale agricultural productivity cannot be reliably quantified (Gornall et al., 2010).

10 Equations (3) and (4) describe the past evolution of agricultural efficiency. These equations will be used in Sect. 3 to extrapolate agricultural efficiency to the future. However, past agriculture was mainly providing food and fibres, whereas future agriculture is likely to become more and more important for the provision of biofuels (in addition to food and fibres). This non-consideration of biofuels may lead to an overestimation of 15 future agricultural efficiency and therefore an overestimation of future wilderness area $(W(y)$ in Eq. 2).

The use of $A_{\text {pers }}(y)$ in Eq. (1) can only be expected to be appropriate for future scenarios where there is a certain degree of globalization of trade and transport of agricultural goods. Future increased scarcity of fossil fuels may reduce this global transport of agricultural goods, thus possibly making Eq. (1) less valid.

\subsubsection{Managed non-agricultural area per person}

In addition to agricultural land, people require land for other purposes such as gardens, buildings, and roads. I estimate that the area per person for non-agricultural purposes $\left(U_{\text {pers }}\right.$ in Eq. 1$)$ is between 273 and $750 \mathrm{~m}^{2}$. The former value is based on The latter value is from De Wit (1967) who derived a global value for $U_{\text {pers }}$ from the region between Boston and Washington DC, which covered a metropolitan area of

ESDD

3, 433-452, 2012

\section{Estimated impact of global population growth on future wilderness extent}

E. Dumont

\section{Title Page}


$27500 \mathrm{~km}^{2}$ and was occupied by 37 million people at that time. I include the value from De Wit (1967) because his study was cited by many subsequent publications on the human carrying capacity of the earth (the most recent being Franck et al., 2011), and because it is a plausible value given the fact that most of the world may have now 5 reached the level of the development that the US had in the 1960s.

\subsubsection{Unsustainable irrigation}

Overexploitation of groundwater water resources (aquifers) occurs in regions of the world where groundwater abstraction rates exceed the groundwater replenishment rates. Irrigation supported by such nonrenewable groundwater is unsustainable in the 10 long term, because it will result in falling groundwater levels which may eventually become unreachable for local farmers.

According to Wada et al. (2012), $18 \%$ of irrigation water used globally in the year 2000 was from nonrenewable groundwater. If this groundwater will have become unreachable in 2050 , then the resulting loss in agricultural production may need to be 15 compensated by rain-fed agriculture which requires more area for the same production. According to Bruinsma (2009), about $42 \%$ of global crop production is from irrigated areas, whereas only $23 \%$ of the global area with harvested crops is irrigated. This indicates that the yield per unit area from irrigated agriculture is about 2.4 times higher than from rain-fed agriculture.

In this study a scenario is modelled in which all nonrenewable groundwater used for irrigation in 2000 will be exhausted by 2050 . The corresponding loss in agricultural production is then regained with new rain-fed agriculture (requiring more area). This scenario may underestimate the actual impact of nonrenewable groundwater use because new overexploitation starting after 2000 is not considered (non-renewable groundwater use more than tripled from 1960 to 2000 , and is likely to keep increasing at a similar rate after 2000; Wada et al., 2012). On the other hand, it is not sure whether all aquifers that are overexploited in 2000 will be exhausted in 2050 . Therefore the impact
ESDD

3, 433-452, 2012

\section{Estimated impact of global population growth on future wilderness extent}

E. Dumont

\section{Title Page}

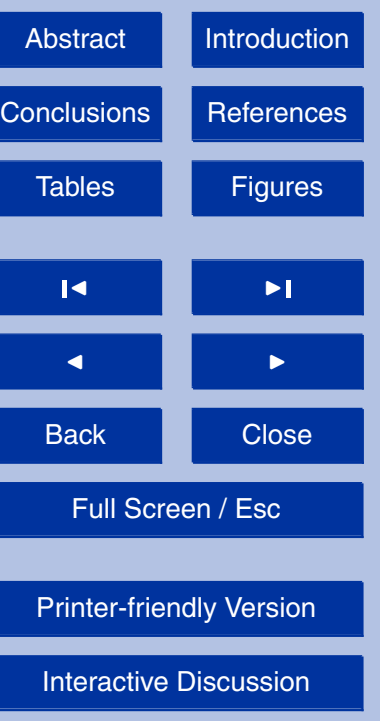

Interactive Discussion 
of unsustainable groundwater use described in this scenario is probably intermediate. This scenario is modelled as follows for each year in the period 2012-2050:

$I(y)=F_{\text {UnsusGW }} \cdot F_{\text {irr }} \cdot\left(R_{\text {yield }}-1\right) \cdot A_{\mathrm{FAO}}(2000) \cdot \frac{y-2012}{2050-2012}$

Here, $F_{\text {UnsusGw }}$ is the fraction of the global irrigation water use that was from nonre5 newable groundwater in the year 2000 (0.18 according to Wada et al., 2012), $F_{\text {irr }}$ is the fraction of the global agricultural area that is irrigated in the year $2000(0.058$ according to FAOSTAT), $R_{\text {yield }}$ is the ratio of yield per unit area for irrigated agriculture over yield per unit area for rain-fed agriculture (2.4 based on Bruinsma, 2009), $A_{\mathrm{FAO}}(2000)$ is the agricultural area in the year 2000 from FAOSTAT $\left(49.4\right.$ million $\left.\mathrm{km}^{2}\right)$.

Equation (5) assumes that $I(y)$ is zero $\mathrm{km}^{2}$ in 2012 and increases linearly with time until it is 0.72 million $\mathrm{km}^{2}$ in the year 2050. This assumption is made because transition from irrigated to rain-fed agriculture due to exhausted groundwater resources is not yet widespread in 2012 (although it has already occurred on a very limited scale, e.g. on the Ogalalla aquifer in the US).

15 Abstraction of nonrenewable groundwater is not the only unsustainable irrigation practice. For example; certain irrigation practices are unsustainable because they cause salinization of the soil. Therefore it is likely that the impact of unsustainable irrigation is underestimated by Eq. (5), which may lead to overestimation of the global wilderness extent by Eq. (2).

\subsection{Land without major extinctions}

Large carnivores are often the species category most prone to extinction. This is due to their large home range requiring large unfragmented wilderness areas, and due to hunting (Woodroffe and Ginsberg, 1998). Woodroffe (2000) showed that there are statistically significant relations between local extinctions of nine large carnivore species and the human population density in the states, districts or counties where these large carnivores lived. I estimated the proportion of the world with a population density low
ESDD

3, 433-452, 2012

\section{Estimated impact of global population growth on future wilderness extent}

E. Dumont

\section{Title Page}

Abstract Introduction

Conclusions References

Tables Figures

14 $\rightarrow$

4

Back

Close

Printer-friendly Version

Interactive Discussion 
enough for half of the large carnivores investigated by Woodroffe (2000) not to go extinct (13 people $\mathrm{km}^{-2}$ ). This was done using a global population grid for the year 2010 from GPWv3 (2005) with a $1 \times 1^{\circ}$ resolution, consistent with the resolution of study of Woodroffe (2000). This map was modified to represent the population distribution in 5 future years up to 2050, in accordance with the three birth-rate scenarios described in Sect. 2.1. This resulted in estimates of the proportion of the world where most large carnivores would not go extinct, and where most other species are not at risk because they are likely to be less prone to extinction than large carnivores.

To represent the fact that local species cannot return after they have become fully 10 extinct, the estimates of total area without major extinctions are transformed using Eq. (2).

\section{Results}

The methods to estimate the future change in drivers of wilderness extent were described previously. The resulting projected change in wilderness extent between 2012 and 2050 is shown in Fig. 3 at five-year intervals, considering two definitions of wilderness (unmanaged land and land without major extinctions, both modified by Eq. 2), and different parameterizations of unmanaged land (Table 1). The difference with the horizontal line at 21.5 million $\mathrm{km}^{2}$ indicates the extent of biodiverse wilderness (as explained in Sect. 2.2).

Figure $3 a$ shows that the area of biodiverse unmanaged land is estimated to reduce with 3.9 to $7.2 \%$ (median $5.4 \%$ ) until 2050. In case of high birth rates, biodiverse unmanaged land is estimated to reduce with $17.5 \%$ (median) (Fig. 3b). Conversely; under low birth rates, it is estimated to reduce with $0.7 \%$ (median) (Fig. 3c).

The contribution of agricultural and non-agricultural area to these reductions is $0.1-$ 258.7 million $\mathrm{km}^{2}$ and $0.3-0.8$ million $\mathrm{km}^{2}$, respectively. The contribution of unsustainable irrigation is 0.7 million $\mathrm{km}^{2}$.
ESDD

3, 433-452, 2012

\section{Estimated impact of global population growth on future wilderness extent}

E. Dumont

\section{Title Page}

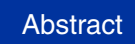

Introduction

Conclusions

References

Tables

Figures

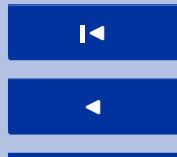

$>1$

Back

Close
Full Screen / Esc

Printer-friendly Version

Interactive Discussion 
The biodiverse area without major extinctions is projected to decrease with $10.5 \%$ (Fig. 3a). Low and high human birth rates reduce biodiverse area without major extinctions with 5.6 and $15.3 \%$, respectively (Fig. $3 b$ and c).

Thus the results indicate that a reduction of expected future birth-rates with up to 50.5 child per woman (UN medium projection versus UN low variant) changes the reduction of biodiverse wilderness by 2050 from 5.4 to $0.7 \%$ if wilderness is defined as biodiverse unmanaged land, or from 10.5 to $5.6 \%$ if wilderness is defined biodiverse land without major extinctions.

\section{Discussion}

10 The range of estimated reductions in biodiverse unmanaged land until 2050 presented in this paper $\left(0.4-20.7\right.$ million $\left.\mathrm{km}^{2}\right)$ is almost identical to the range of estimates of decline of natural area (similar to biodiverse unmanaged land in this study) found in literature by Smith et al. (2010). This gives some confidence to the results presented in this paper.

15 Nevertheless, this study may underestimate future reduction in wilderness area because it has not accounted for the increasing impact of land degradation on wilderness extent, and for the impacts of climate change.

This study indicates that future population growth is likely to be devastating for wilderness, even though human population growth is projected to decelerate in this millen-

nium. Therefore this issue should be addressed more by science and policymakers. Especially since there are ways to reduce population growth such as improving access to contraception in developing countries. Further, there is empirical evidence suggesting that reduced fertility is linked to improved education (Bledsoe et al., 1999; Osili and Long, 2007). Environmental science can put population on the public agenda by explic25 itly linking environmental problems to population if population drives these problems. For various reasons population growth is not mentioned in scientific publications as an underlying cause of problems, which has caused that media and policy makers have

\section{ESDD}

3, 433-452, 2012

\section{Estimated impact of global population growth on future wilderness extent}

E. Dumont

\section{Title Page}

\section{4}


largely ignored this driver as well (Johnson, 2007; Maher, 1977). However the results of this study indicate the importance of population growth as a driver for wilderness decline and the need to focus more attention to this driver.

\section{Main conclusions}

5 This study has indicated that birth rate is an important factor influencing both the quality and quantity of wilderness remaining in the world in the future. A decrease of up to 0.5 child per woman from the expected global birth-rate evolution until 2050 is estimated to save about $4.8 \%$ of the biodiverse wilderness area in the world. Conversely, an increase of up to 0.5 child per woman from the expected global birth-rate evolu10 tion until 2050 is estimated to cause an additional destruction of 4.8 to $12.1 \%$ of the biodiverse wilderness area in the world.

Acknowledgements. The author thanks Iwona Cisowska for providing useful comments on a draft of this paper.

\section{References}

Bledsoe, C. H., Casterline, J. B., Johnson-Kuhn, J. A., and Haaga, J. G.: Critical perspectives on schooling and fertility in the developing world, National Academy Press, Washington, D.C., 1999.

Bruinsma, J.: The resource outlook to 2050: by how much do land, water and crop yields need to increase by 2050?, FAO Expert Meeting on "How to Feed the World in 2050", Rome, $20 \quad$ 24-26 June 2009.

De Wit, C. T.: Photosynthesis: its relationship to overpopulation, in: Harvesting the Sun: Photosynthesis in Plant Life, edited by: San Pietro, A., Greer, F. A., and Army, J. T., Academic Press, NY, 315-320, 1967.

Dobrovolski, R., Alexandre Felizola Diniz-Filho, J., Dias Loyola, R., and De Marco Jr., P.: Agri-

\section{ESDD}

3, 433-452, 2012

\section{Estimated impact of global population growth on future wilderness extent}

E. Dumont

\section{Title Page}

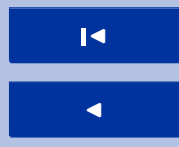

\section{Full Screen / Esc}

Printer-friendly Version

Interactive Discussion 
FAOSTAT: http://faostat.fao.org, last access: January 2012.

Fischer, G., van Velthuizen, H., Shah, M., and Nachtergaele, F.: Global Agro-ecological Assessment for Agriculture in the 21st Century: Methodology and Results, Research report, IIASA, Laxenburg, Austria, 2002.

5 Franck, S., von Bloh, W., Muller, C., Bondeau, A., and Sakschewski, B.: Harvesting the sun: New estimates of the maximum population of planet earth, Ecol. Model., 222, 2019-2026, 2011.

GAEZ: http://www.iiasa.ac.at/Research/LUC/GAEZ/ (last access: January 2012), 2000.

Gornall, J., Betts, R., Burke, E., Clark, R., Camp, J., Willet, K., and Wiltshire, A.: Implications of climate change for agricultural productivity in the early twenty-first century, Philos. T. Roy. Soc. B., 365, 2973-2989, 2010.

GPWv3: http://sedac.ciesin.columbia.edu/gpw/ (last access: March 2012), 2005.

Houghton, R. A.: The Worldwide Extent of Land-Use Change, BioScience, 44, 305-313, 1994.

Johnson, B.: http://www.telegraph.co.uk/comment/3643551/Global-over-population-is-the-real-issue.html (last access: June 2012), 2007.

Kleidon, A. and Mooney, H. A.: A global distribution of biodiversity inferred from climatic constraints: results from a process-based modelling study, Global Change. Biol., 6, 507-523, 2008.

Klein Goldewijk, K., Beusen, A., van Drecht, G., and de Vos, M.: The HYDE 3.1 spatially explicit database of human-induced global land-use change over the past 12,000 years, Global Ecol. Biogeogr., 20, 73-86, 2011.

Maher, M. T.: How and why journalists avoid the population-environment connection, Popul. Environ., 18, 339-372, doi:10.1007/BF02208512, 1977.

Mittermeier, R. A., Mittermeier, C. G., Brooks, T. M., Pilgrim, J. D., Konstant, W. R., da Fonseca, G. A. B., and Kormos, C.: Wilderness and biodiversity conservation, P. Natl. Acad. Sci. USA, 100, 10309-10313, 2003.

Noss, R. F.: Sustainability and Wilderness, Conserv. Biol., 5, 120-122, 1991.

Osili, U. O. and Long, B. T.: Does female schooling reduce fertility? Evidence from Nigeria, NBER working paper series, Working Paper 13070, National Bureau of Economic Research, Cambridge, USA, 2007.

Rubel, F. and Kottek, M.: Observed and projected climate shifts 1901-2100 depicted by world maps of the Köppen-Geiger climate classification, Meteorol. Z., 19, 135-141, doi:10.1127/0941-2948/2010/0430, 2010.
ESDD

3, 433-452, 2012

\section{Estimated impact of global population growth on future wilderness extent}

E. Dumont

\section{Title Page}

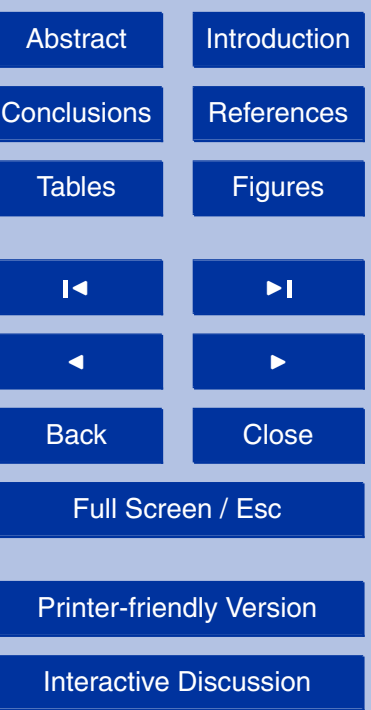

Interactive Discussion 
Smith, P., Gregory, P. J., van Vuuren, D., Obersteiner, M., Havlík, P., Rounsevell, M., Woods, J., Stehfest, E., and Bellarby, J.: Competition for land, Philos. T. Roy. Soc. B, 365, 2941-2957, doi:10.1098/rstb.2010.0127, 2010.

UN: Assumptions underlying the 2010 revision, United Nations Population Division, NY, 2010.

5 Van den Bergh, J. C. J. M. and Rietveld, P.: Reconsidering the Limits to World Population: Meta-analysis and Meta-prediction, BioScience, 54, 195-204, 2004.

Wada, Y., van Beek, L. P. H., and Bierkens, M. F. P.: Nonsustainable groundwater sustaining irrigation: A global assessment, Water Resour. Res., 48, W00L06, doi:10.1029/2011WR010562, 2012.

10 Woodroffe, R.: Predators and people: using human densities to interpret declines of large carnivores, Anim. Conserv., 3, 165-173, 2000.

Woodroffe, R. and Ginsberg, J. R.: Edge effects and the extinction of populations inside protected areas, Science, 280, 2126-2128, 1998.

ESDD

3, 433-452, 2012

\section{Estimated impact of global population growth on future wilderness extent}

E. Dumont

\section{Title Page}

Abstract

Conclusions

Tables

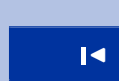

4

Back

Full Screen / Esc

Printer-friendly Version

Interactive Discussion

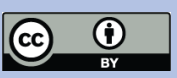




\section{ESDD}

3, 433-452, 2012

\section{Estimated impact of global population growth on future wilderness extent}

E. Dumont

Table 1. Parameters which vary between the different simulations of future wilderness extent.

\begin{tabular}{lllll}
\hline Parameter & Unit & Value & Source & Simulation \\
\hline$c_{1}$ & $\mathrm{~km}^{2}$ & $-1.73 \times 10^{8}$ & Based on FAOSTAT (2012) & 1,3 \\
$c_{1}$ & $\mathrm{~km}^{2}$ & $-2.32 \times 10^{8}$ & Bruinsma (2009) & 2,4 \\
$c_{2}$ & $\mathrm{~km}^{2} \mathrm{yr}^{-1}$ & $1.11 \times 10^{5}$ & Based on FAOSTAT (2012) & 1,3 \\
$c_{2}$ & $\mathrm{~km}^{2} \mathrm{yr}^{-1}$ & $1.41 \times 10^{5}$ & Bruinsma (2009) & 2,4 \\
$U_{\text {pers }}$ & $\mathrm{km}^{2}$ & $2.73 \times 10^{-4}$ & based on GAEZ (2000) & 1,2 \\
$U_{\text {pers }}$ & $\mathrm{km}^{2}$ & $7.5 \times 10^{-4}$ & De Wit (1967) & 3,4 \\
\hline
\end{tabular}

Title Page

Abstract Introduction

Conclusions

References

Tables

Figures

14

4

Back

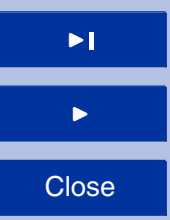

Full Screen / Esc

Printer-friendly Version

Interactive Discussion 


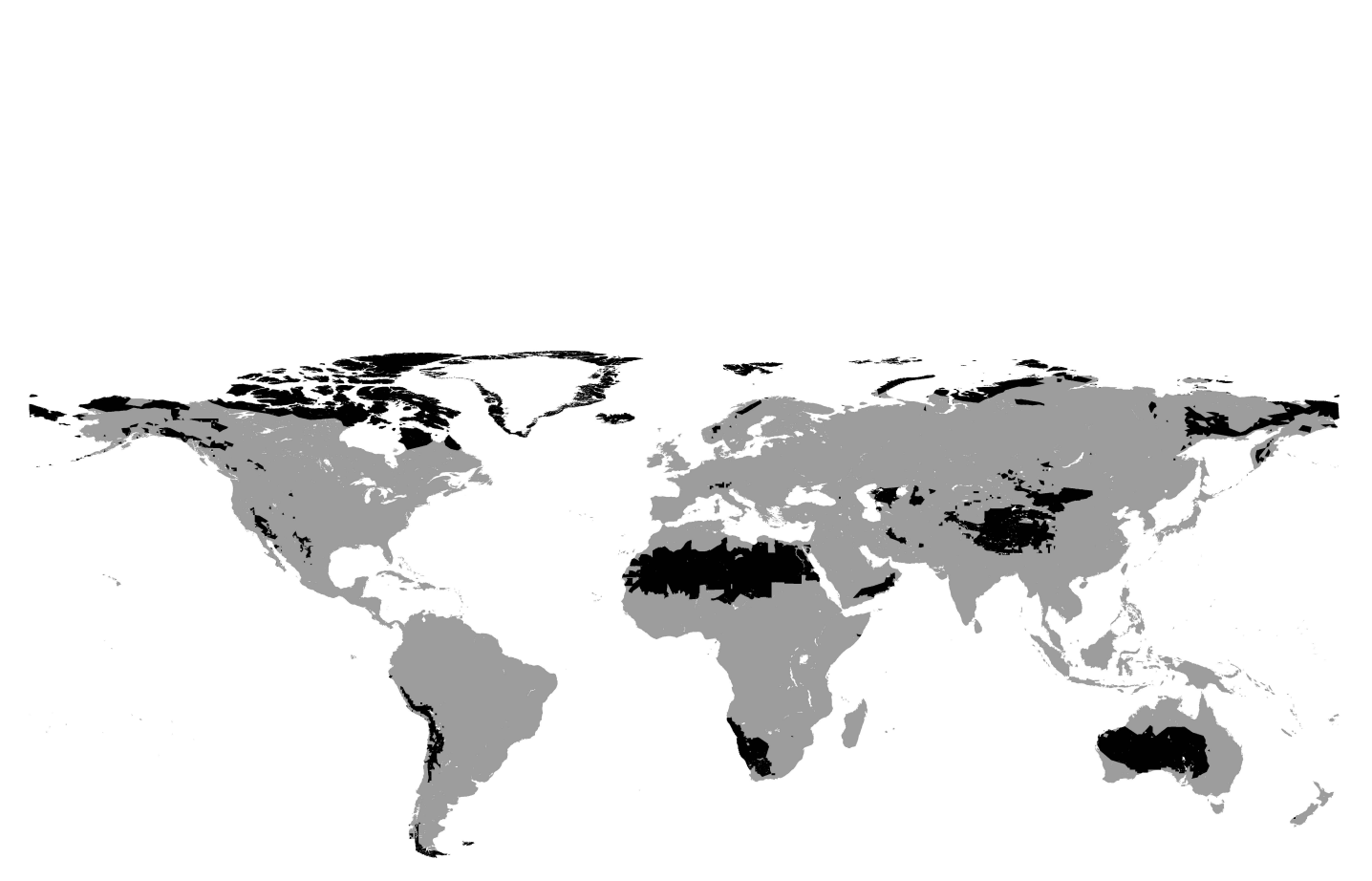

Fig. 1. Areas with low bio-diversity that are not expected to have significant future change in wilderness extent due low population density and unsuitability for agriculture (shown in black). The remaining ice-free land area is shown in grey.

\section{ESDD}

3, 433-452, 2012

\section{Estimated impact of global population growth on future wilderness extent}

E. Dumont

Title Page
Abstract

Conclusions

Tables

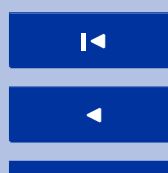

Back

Full Screen / Esc

Printer-friendly Version

Interactive Discussion 


\section{ESDD}

3, 433-452, 2012

\section{Estimated impact of global population growth on future wilderness extent}

E. Dumont

Fig. 2. Trend in global agricultural area since 1960 according to FAOSTAT (2012) (a). Trend in global agricultural area if agricultural efficiency (persons per unit agricultural area) would not have increased since 1960 (b). Here agricultural area is defined as the sum of the surface areas of grassland and arable land.
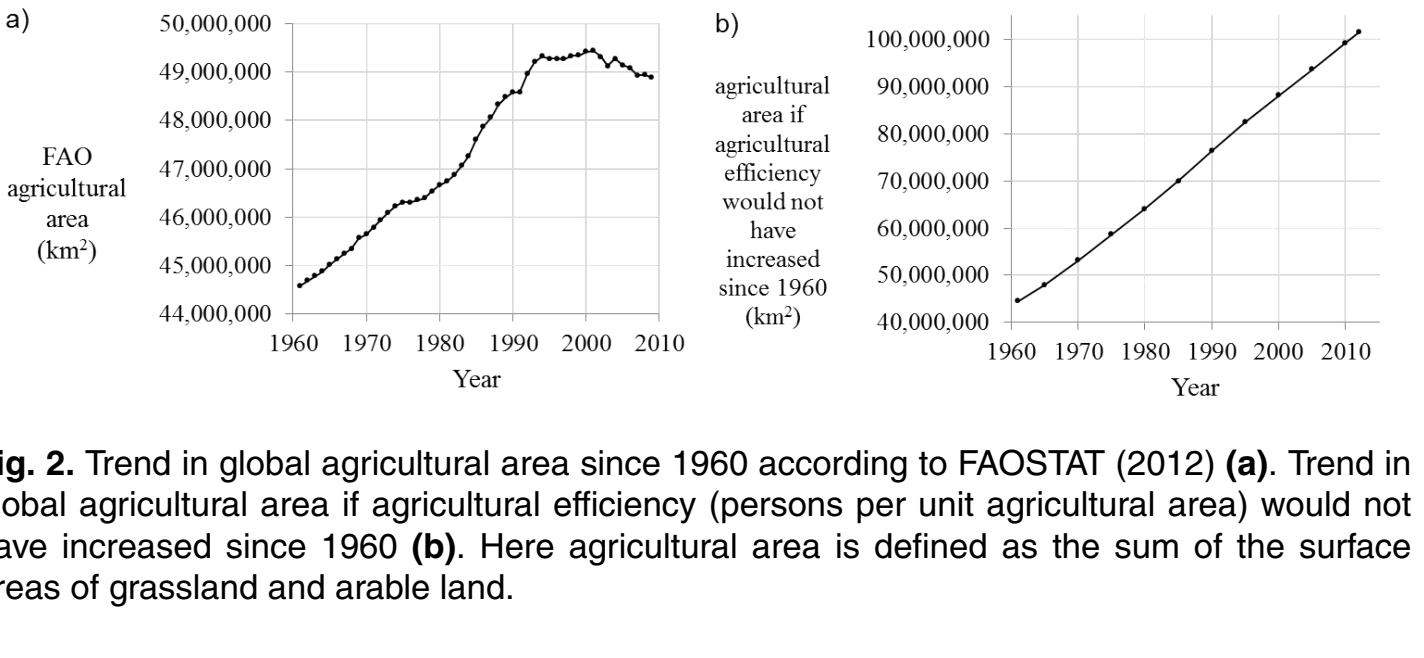
a)

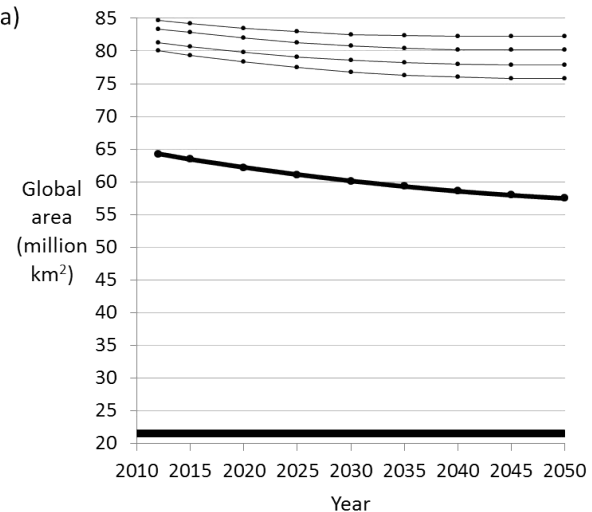

c)

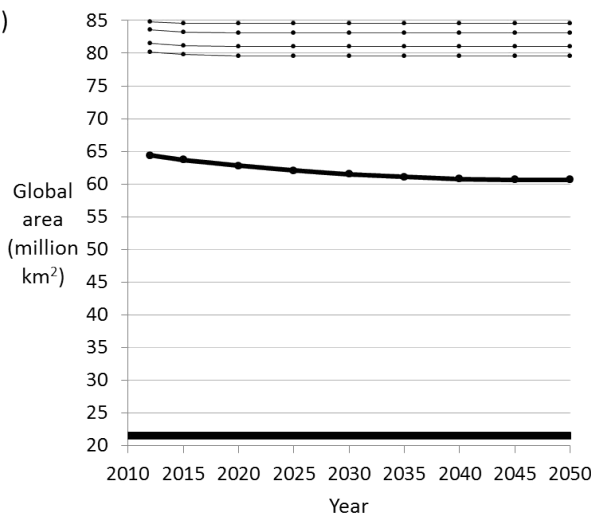

b)

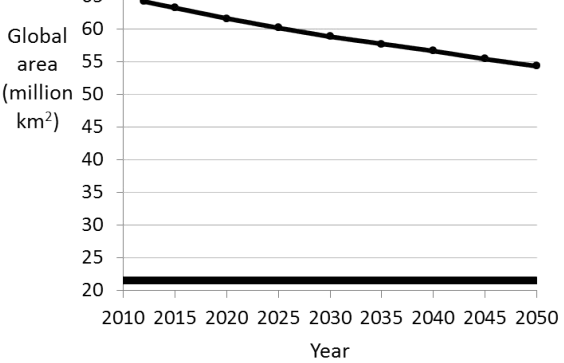

- Unmanaged land

-Land without major extinctions

Low biodiversity areas with low wilderness losses
ESDD

3, 433-452, 2012

\section{Estimated impact of global population growth on future wilderness extent}

E. Dumont

Title Page

Abstract Introduction

Conclusions

References

Tables Figures
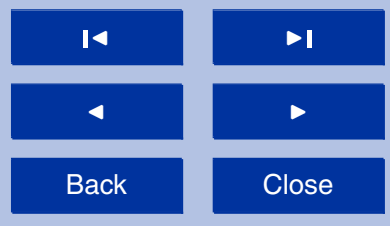

Back

Full Screen / Esc

Fig. 3. Different projected future trends in global wilderness area, and the future trend in the part of this area without major extinctions. The different panels indicate these trends for different birth rates: UN medium variant (a), UN high variant (b), UN low variant (c). Each panel also indicates the proportion of the world with low biodiversity and where no significant wilderness loss is expected (explained in Sect. 2.2). In order from top to bottom, the thin lines (unmanaged land) indicate simulation 1, 2, 3, and 4 (Table 1).
Printer-friendly Version

Interactive Discussion 